\title{
Age of First Cigarette, Alcohol, and Marijuana Use Among U.S. Biracial/Ethnic Youth: A Population-Based Study
}

\author{
Trenette T. Clark, PhD, LCSW ${ }^{1}$, \\ University of North Carolina at Chapel Hill \\ Otima Doyle, PhD, and \\ University of Illinois at Chicago \\ Amanda Clincy, PhD \\ University of North Carolina at Chapel Hill
}

\begin{abstract}
This study examines age of first cigarette, alcohol, and marijuana use among self-identified biracial youth, using data from the National Longitudinal Study of Adolescent Health (Add Health). We found an intermediate biracial phenomenon in which some biracial youth initiate substance use at ages that fall between the initiation ages of their 2 corresponding monoracial groups. When controlling for the covariates, our findings show White-Asian biracial youth begin smoking marijuana and drinking alcohol at earlier ages than Whites and engaging in all forms of substance use at earlier ages than Asian youth. Results indicate White-American Indian youth start smoking cigarettes at earlier ages than all biracial and monoracial groups. Our findings underscore the need for future research to examine substance-use initiation and progression among biracial/ ethnic youth.
\end{abstract}

\section{Keywords}

substance initiation; onset; tobacco; nicotine; drugs; parents

\section{Introduction}

The bulk of empirical evidence related to initiation of substance use relates to White youth, and followed by research on monoracial/ethnic minority youth. Despite documented racial/

\footnotetext{
(C) 2013 Elsevier Ltd. All rights reserved.

${ }^{1}$ Corresponding Author: Trenette T. Clark, PhD, LCSW, Assistant Professor, University of North Carolina at Chapel Hill, School of Social Work, 325 Pittsboro Street, CB 3550, Chapel Hill, NC 27599, 919-843-8020 (voice), ttclark@email.unc.edu.

Contributors

The first author conceptualized the study, performed data analysis, and wrote sections of the manuscript. The second and third authors wrote sections of the manuscript.

Conflict of Interest

The authors declare that they have no conflicts of interest.

Publisher's Disclaimer: This is a PDF file of an unedited manuscript that has been accepted for publication. As a service to our customers we are providing this early version of the manuscript. The manuscript will undergo copyediting, typesetting, and review of the resulting proof before it is published in its final citable form. Please note that during the production process errors may be discovered which could affect the content, and all legal disclaimers that apply to the journal pertain.
} 
ethnic disparities in substance-use and related problems, little is known about substance initiation among the 5.2 million biracial individuals in the United States-a population projected to triple by 2050 (U.S. Census Bureau, 2008). Many biracial youth experience extraordinary stress stemming from their biracial identity, and this stress likely has an impact on their coping styles (Gibbs \& Huange, 2003; Udry, Li, \& Hendrickson-Smith, 2003). Compared with monoracial youth, biracial youth are generally at higher risk for health and behavioral problems, including substance use (Udry et al., 2003). However, research examining the epidemiology and etiology of substance use among biracial youth is scarce.

The onset of cigarette, alcohol, and marijuana use typically occurs during adolescence. In addition, early use is associated with social, behavioral, and mental health outcomes (Henry et al., 2011; Peleg-Oren, Saint-Jean, Cardenas, Tammara, \& Pierre, 2009) as well as serious physical health consequences (Jacobus, Bava, Cohen-Zion, Mahmood, \& Tapert, 2009). Understanding the influence of race/ethnicity, particularly biracialism, on substance initiation can inform prevention efforts for an increasingly visible group in America.

Our study goals were (a) to compare the age of substance-use initiation of biracial/ethnic youth with monoracial/ethnic youth and (b) to examine the influence of sociodemographic variables on age of substance-use initiation. Because parents can be instrumental in delaying children's substance-use initiation (Hirschi, 1969; Moos, 2007) and parental influence might be particularly important for biracial youth (Choi, Harachi, Gillmore, \& Catalano, 2006), we also examined the influence a close parent-child relationship has on substance-use initiation. We hypothesized that age of substance-use initiation for each biracial subgroup was intermediate to that of their two monoracial counterparts.

\section{Method}

\subsection{Study Design and Sample}

Add Health is a population-based longitudinal study that has followed a U.S. sample from adolescence to adulthood. The sample was drawn from 80 high schools and 52 middle schools that were selected through a stratified random sampling process. Add Health has collected four waves of data: Wave 1 during 1994 and 1995 (when participants were ages 11-21 years), Wave 2 in 1996 (ages 12-22), Wave 3 during 2001 and 2002 (ages 18-28) and Wave 4 (ages 24-34) during 2007 and 2008. Add Health details are available elsewhere (see Harris et al., 2009).

\subsection{Measurement of Dependent Variables}

2.2.1 Substance Use-This study examined variation in self-reported age of first cigarette, alcohol, and marijuana use. Waves 1 and 4 used identical questions to ask respondents to recall their age at first use of each substance: "How old were you when you smoked a whole cigarette for the first time?"; "How old were you when you first had an alcoholic drink?"; and "How old were you when you first tried marijuana?" Waves 2 and 3 did not ask about first use. If respondents reported substance use at Wave 1, we used that reported age of first use as our dependent variable. If no use was reported at Wave 1 but substance use was reported at Wave 2, we used the respondent's actual age at Wave 2 as the 
age of initiation variable, because Wave 2 data were collected within a year of Wave1. For non-users in Waves 1 and 2 who reported use in Waves 3 or 4, we used their Wave 4 reported age of first use. If respondents had not used the substance in any Wave, they were coded as non-users.

\subsection{Measurement of Independent Variables}

2.3.1. Race/Ethnicity-Adolescents were asked to identify their race/ethnicity in Waves 1 and 3. If available, we used the Wave 3 race/ethnicity data for respondents. For cases missing Wave 3 race data, we used self-reports of their race/ethnicity from Wave 1 . We considered five major racial/ethnic categories: White, Black, Hispanic, Asian, and American Indian as well as the biracial/ethnic combinations of these categories, such as White-Black or Hispanic-Asian. Monoracial youth are youth who reported only one race/ethnicity (e.g., non-Hispanic White). Biracial/ethnic youth are youth who reported two races/ethnicities (e.g., Black-White. Hispanic-American Indian). In total, we considered 16 categories: 15 unique pairwise combinations of the racial/ethnic identifications and a multiracial/ethnicity/ other category of respondents who identified with multiple races/ethnicities (e.g., Black, White, and Hispanic) or no race/ethnicity. The multi/other category was used to identify the effects of the other groups. However, comparisons with the multi/other group are not reported because the group's heterogeneity limited our ability to draw conclusions about individuals in this group.

2.3.2. Closeness to Mother and Father-Respondents provided separate ratings of how close they felt to their mother and father. Responses used a 5-point scale ranging from not at all close (1) to very close (5).

2.3.3. Covariates-Covariates used as controls included age at Wave 1, gender, family socioeconomic status (SES; measured as parental education), family structure (living with one or two biological parents), community type (urban, suburban, rural), and U.S. region.

\subsection{Statistical Analyses}

Add Health's Wave 1 survey weights were used to adjust the regression resultsThe primary methodology utilized in the present study is Tobit regression with sample weights. The dependent variables involve two questions: Has the respondent ever used the substance? If so, how old was the respondent at first use? The Tobit results are interpreted as linear regression results but they account for the selection of the respondents to use the substance. Non-users are treated as if they have not yet used the substance.

\section{Results}

Table 1 reports the average age at first-use of cigarettes, alcohol, and marijuana for each racial/ethnic group. In addition, the table shows the frequency of substance and percentage of each group's use of each substance. Tobit regression results are presented in Table 2, including age of use of cigarettes, alcohol, and marijuana while controlling for covariates. As noted in 2.2.1, the dependent variable is age of first substance use; therefore, positive 
coefficients indicate the independent variable influences participants to delay substance initiation until later in life or not at all.

Our findings suggest that a close parent-child relationship is significantly associated with the age of first use of all three substances. Participants who reported being close to their mother, father, or both parents tended to be significantly older when they first used any of the three substances, and more frequently never used these substances.

In comparing differences by race/ethnicity, White was the reference group; thus, coefficients for other racial/ethnic groups are in comparison with the White group. As compared with Whites, respondents who were Black, Asian, White-Hispanic, Black-Asian, and HispanicAmerican Indian reported first smoking cigarettes at significantly older ages. However, White-American Indians reported initiating cigarette use at significantly younger ages than Whites. No groups reported alcohol initiation younger than Whites, and the Black, Asian, and White-Hispanic groups reported first drinking alcohol significantly later in life than Whites. Both the Black and Asian groups reported first use of marijuana significantly later in life than Whites, whereas biracial White-Asians first used marijuana when significantly younger than Whites.

Although comparison with the White group is helpful in understanding trends in substance use among racial/ethnic subgroups, other between-group comparisons are needed to fully understand the dynamics. Further, significance tests are only partially illuminating; we can use Tobit results to estimate between-group differences in average age of first use to assess for clinical importance. Table 1 highlights differences between biracial groups and the corresponding monoracial groups in average age of substance-use initiation. These comparisons examined average age of first use of cigarettes, alcohol, and marijuana while controlling for the covariates. Positive numbers indicate the monoracial group had a higher average age of initiation; that is, the group tended to begin using the substance later in life than members of the biracial/ethnic group. Conversely, negative numbers imply that members of the biracial/ethnic group tended to begin using the substance later in life than members of the monoracial group. For example, when controlling for the covariates, WhiteAmerican Indian respondents tended to begin smoking cigarettes 1.2 years earlier than Whites, used marijuana .6 years earlier than Whites, and began drinking alcohol at the same age as Whites. Comparisons of Blacks and Black-American Indians showed that BlackAmerican Indians smoked cigarettes 1.5 years earlier than Blacks and used marijuana 1.3 years earlier than Blacks, but began drinking alcohol 1 year later than Blacks. Comparisons of Hispanics and Hispanic-Asians showed that Hispanic-Asians typically initiated cigarette smoking .06 years later than Hispanics, began drinking alcohol 3.2 years later than Hispanics, and began smoking marijuana 2 years later than Hispanics. Among Asian and White-Asian respondents, comparisons showed that White-Asians smoked cigarettes 1.1 years earlier than Asians, drank alcohol 2.3 years earlier than Asians, and smoked marijuana 3.8 years earlier than Asians. Among American Indian and Hispanic-American Indian respondents, comparisons revealed that Hispanic-American Indians smoked cigarettes 3.2 years later than American Indians, drank alcohol 1.7 years later than American Indians, and smoked marijuana 1.8 years later than American Indians. 
Studies such as Grant and Dawson (1998) have found that after controlling for demographic covariates, the likelihood of substance abuse and dependence is reduced with each year that substance use onset is delayed. Therefore, using substances one year early carries greater health and social consequences. As a result, the findings in Table 1 that reflect earlier substance use by 1 year or more for a group of adolescents are particularly important for practice and prevention. These particular findings are underlined and bolded in Table 1.

\section{Discussion}

In general, biracial individuals follow Whites with the second highest prevalence rates of substance use (SAMHSA, 2008). Oftentimes when studies examine racial differences in substance use prevalence rates, biracial subgroups are combined into a single group. This aggregation masks important subgroup differences that have implications for prevention and intervention. In support of this notion, the findings of the current study suggest that biracial youth are highly diverse in terms of their substance use initiation. When controlling for covariates, biracial subgroups initiated substance use at ages earlier, later, or similar to White youth. For example and interestingly, White-American Indians started smoking cigarettes at earlier ages than all monoracial and biracial groups. Also, biracial White-Asian youth began smoking marijuana and drinking alcohol at earlier ages than Whites and engaging in all forms of substance use earlier than Asian youth.

These subgroups appear to be particularly vulnerable to early substance use initiation. It may be that these subgroups struggle with forming adaptive coping strategies to combat the unique conflicts related to biracial identity (Gibbs \& Huange, 2003), making them more susceptible to early substance use initiation. However, future research is needed to explore associations between ethnic identity development in biracial youth and substance use initiation.

Consistent with previous research, we found an intermediate biracial phenomenon (Authors, in press; Udry et al., 2003). That is, biracial youth seem to initiate substance use at ages approximately mid-way between the initiation ages of their two corresponding monoracial groups. For example, White-Black youth began smoking at about 14.8 years, which is older than Whites (14.3 years) but younger than Blacks (15.7 years). However, this pattern did not hold when covariates (e.g., gender, SES, family structure, community type) were entered into the model. Only 3 of 9 biracial groups-Black-Hispanics, Black-American Indians, and White-American Indian - maintained the same intermediate age of substance initiation beyond the effects of sociodemographic characteristics and closeness to parents. This finding suggests that biracial status itself does not necessarily confer risk, particularly for all biracial groups. Indeed, for some groups, the risk of substance-use initiation appears to stem from the sociodemographic and environmental contexts in which the youth are embedded.

\section{Conclusion}

This study is the first to estimate and compare age of substance initiation among monoracial/ ethnic and biracial/ethnic individuals in a nationally representative sample. The results highlight the need for a stronger focus on substance use among biracial youth and a better understanding of the broader ecological contexts in which these youth reside. When biracial 
youth are examined in aggregate, potential subgroup differences are masked that could help researchers develop targeted interventions. Further, knowing whether the age of initiation of a biracial group is closer to one race versus the other might help practitioners identify shared experiences, such as those related to ethnic identity development contributing to early or late substance-use initiation. This information can provide entry points for targeted intervention and prevention efforts. Although understanding general factors that protect youth from early substance-use initiation (e.g., close parent-child relationships) is important, additional research is needed to clarify the experiences that biracial youth share with one, both, or neither of their constituent racial/ethnic groups that might contribute to substance use.

\title{
Acknowledgments
}

\author{
Role of Funding Sources
}

Funding for this study was provided by a Junior Faculty Development Award, Office of the Executive Vice Chancellor and Provost, University of North Carolina at Chapel Hill and a University Research Council Research Grant, Office of the Vice Chancellor for Research and Economic Development, University of North Carolina at Chapel Hill awarded to the first author.

The authors wish to thank Jonathan Kropko for his assistance with data management.

This research uses data from Add Health, a program project directed by Kathleen Mullan Harris and designed by J. Richard Udry, Peter S. Bearman, and Kathleen Mullan Harris at the University of North Carolina at Chapel Hill, and funded by grant P01-HD31921 from the Eunice Kennedy Shriver National Institute of Child Health and Human Development, with cooperative funding from 23 other federal agencies and foundations. Special acknowledgment is due Ronald R. Rindfuss and Barbara Entwisle for assistance in the original design. Information on how to obtain the Add Health data files is available on the Add Health website (http://www.cpc.unc.edu/addhealth). No direct support was received from grant P01-HD31921 for this analysis.

\section{References}

Choi Y, Harachi TW, Gillmore MR, Catalano R. Are multiracial adolescents at greater risk? Comparisons of rates, patterns, and correlates of substance use and violence between monoracial and multiracial adolescents. Journal of Orthopsychiatry. 2006; 76:86-97. http://dx.doi.org/ 10.1037/0002-9432.76.1.86.

Gibbs, JT.; Huange, LN. Children of color: Psychological interventions with culturally diverse youth. 2. San Francisco, CA: Jossey-Bass; 2003.

Grant BF, Dawson DA. Age of onset of drug use and its association with DSM-IV drug abuse and dependence: Results from the National Longitudinal Alcohol Epidemiologic Survey. Journal of Substance Abuse. 1998; 10(2):163-173. [PubMed: 9854701]

Harris, KM.; Halpern, CT.; Whitsel, E.; Hussey, J.; Tabor, J.; Entzel, P.; Udry, JR. The National Longitudinal Study of Adolescent Health: Research design. 2009. Retrieved from http:// www.cpc.unc.edu/projects/addhealth/design

Henry, KL.; McDonald, JN.; Oetting, ER.; Silk Walker, P.; Walker, RD.; Beauvais, F. Age of onset of first alcohol intoxication and subsequent alcohol use among urban American Indian adolescents. Psychology of Addictive Behaviors. 2011. http://dx.doi.org/10.1037/a0021710

Hirschi, T. Causes of delinquency. Berkely, CA: University of California Press; 1969.

Jacobus J, Bava S, Cohen-Zion M, Mahmood O, Tapert SF. Functional consequences of marijuana use in adolescents. Pharmacology, Biochemistry and Behavior. 2009; 92:559-565. http://dx.doi.org/ 10.1016/j.pbb.2009.04.001.

Moos RH. Theory-based processes that promote the remission of substance use disorders. Clinical Psychology Review. 2007; 27:537-551. http://dx.doi.org/10.1016/j.cpr.2006.12.006. [PubMed: 17254686] 
Peleg-Oren N, Saint-Jean G, Cardenas GA, Tammara H, Pierre C. Drinking alcohol before age 13 and negative outcomes in late adolescence. Alcoholism: Clinical and Experimental Research. 2009; 33:1966-1972. http://dx.doi.org/10.1111/j.1530-0277.2009.01035.x.

(SAMHSA) Substance Abuse and Mental Health Services Administration. Results from the 2010 National Survey on Drug Use and Health: Summary of national findings. Rockville, MD: 2011. (NSDUH Series H-41 [HHS Publication No. SMA 11-4658])Retrieved from http:// www.samhsa.gov/data/NSDUH/2k10NSDUH/2k10Results.htm

Udry JR, Li RM, Hendrickson-Smith J. Health and behavior risks of adolescents with mixed-race identity. American Journal of Public Health. 2003; 93:1865-1870. http://dx.doi.org/10.2105/ AJPH.93.11.1865. [PubMed: 14600054]

U. S. Census Bureau. An older more diverse national by midcentury. 2008. Retrieved from http:// www.census.gov/newsroom/releases/archives/population/cb08-123.html 


\section{Highlights}

- We found an intermediate biracial phenomenon.

- White-American Indian youth start smoking cigarettes earlier than all groups.

- White-Asian youth begin smoking marijuana and drinking at earlier ages than Whites.

- White-Asian youth engaged in all substances at earlier ages than Asian youth. 


\section{Table 1}

Average Sample Age of First Use, Average Predicted Age of First use, and Differences in Age of Substance Use Onset Between Monoracial and Biracial Youth

\begin{tabular}{|l|l|l|l|}
\hline \multirow{2}{*}{ Race/Ethnicity Wave 1 Sample Size } & \multicolumn{3}{|l|}{ Average Sample Age of First Use / Percent Who Have Ever Used } \\
\cline { 2 - 4 } & Cigarette & Alcohol & Marijuana \\
\hline White $(\mathrm{N}=10,487)$ & $14.3(79.1 \%)$ & $14.9(84.1 \%)$ & $15.8(58.5 \%)$ \\
\hline Black $(\mathrm{N}=4,391)$ & $15.7(60.3 \%)$ & $15.7(65.6 \%)$ & $15.5(46.9 \%)$ \\
\hline Hispanic $(\mathrm{N}=611)$ & $14.5(63.7 \%)$ & $15.2(66.0 \%)$ & $14.7(45.7 \%)$ \\
\hline Asian $(\mathrm{N}=1,321)$ & $15.8(61.9 \%)$ & $16.1(67.9 \%)$ & $16.8(38.8 \%)$ \\
\hline American Indian $(\mathrm{N}=148)$ & $13.7(81.1 \%)$ & $13.9(76.4 \%)$ & $13.5(64.2 \%)$ \\
\hline White-Black (N=135) & $14.8(75.6 \%)$ & $15.0(80.0 \%)$ & $16.0(65.9 \%)$ \\
\hline White-Hispanic $(\mathrm{N}=2,202)$ & $15.2(68.4 \%)$ & $15.2(74.6 \%)$ & $15.6(48.2 \%)$ \\
\hline White-Asian $(\mathrm{N}=145)$ & $14.6(73.1 \%)$ & $14.9(78.6 \%)$ & $15.2(64.8 \%)$ \\
\hline White-American Indian $(\mathrm{N}=312)$ & $13.5(85.3 \%)$ & $14.3(81.4 \%)$ & $15.4(64.4 \%)$ \\
\hline Black-Hispanic $(\mathrm{N}=154)$ & $15.0(69.5 \%)$ & $15.6(73.4 \%)$ & $15.7(51.3 \%)$ \\
\hline Black-Asian $(\mathrm{N}=26)$ & $16.3(69.2 \%)$ & $16.2(73.1 \%)$ & $14.9(57.7 \%)$ \\
\hline Black-American Indian $(\mathrm{N}=85)$ & $15.1(63.5 \%)$ & $15.4(62.4 \%)$ & $15.1(52.9 \%)$ \\
\hline Hispanic-Asian (N=121) & $15.0(67.8 \%)$ & $15.3(67.8 \%)$ & $15.3(49.6 \%)$ \\
\hline Hispanic-American Indian $(\mathrm{N}=355)$ & $15.1(73.8 \%)$ & $15.3(75.2 \%)$ & $14.5(55.8 \%)$ \\
\hline Multi/Other (N=250) & $15.0(72.0 \%)$ & $14.5(70.8 \%)$ & $15.1(54.4 \%)$ \\
\hline
\end{tabular}

\begin{tabular}{|c|c|c|c|}
\hline $\begin{array}{l}\text { Difference between Monoracial and Biracial Groups in } \\
\text { Predicted Average Age of Substance Use Onset }\end{array}$ & Cigarette & Alcohol & Marijuana \\
\hline White - White-Black & $17.10-20.38=\underline{-\mathbf{3 . 2 8}}$ & $16.68-17.66=\underline{-\mathbf{0 . 9 8}}$ & $19.13-19.87=\mathbf{- 0 . 7 4}$ \\
\hline White - White-Hispanic & $17.10-18.15=\underline{-\mathbf{1 . 0 5}}$ & $16.68-17.53=-\mathbf{0 . 8 5}$ & $19.13-19.46=\mathbf{- 0 . 3 3}$ \\
\hline White - White-Asian & $17.10-17.56=-\mathbf{0 . 4 6}$ & $16.68-16.27=\mathbf{0 . 4 1}$ & $19.13-17.38=\underline{\mathbf{1 . 7 5}}$ \\
\hline White - White-American Indian & $17.10-15.89=\underline{\mathbf{1 . 2 1}}$ & $16.68-16.68=\mathbf{0}$ & $19.13-18.55=\mathbf{0 . 5 8}$ \\
\hline Black - White-Black & $20.04-20.38=\mathbf{- 0 . 3 4}$ & $18.98-17.66=\underline{\mathbf{1 . 3 2}}$ & $20.57-19.87=\mathbf{0 . 7 0}$ \\
\hline Black - Black-Hispanic & $20.04-18.94=\underline{\mathbf{1 . 1 0}}$ & $18.98-18.06=\mathbf{0 . 9 2}$ & $20.57-19.89=\mathbf{0 . 6 8}$ \\
\hline Black - Black-Asian & $20.04-23.59=-\underline{\mathbf{3 . 5 5}}$ & $18.98-16.79=\underline{\mathbf{2 . 1 9}}$ & $20.57-23.62=-\underline{\mathbf{3 . 0 5}}$ \\
\hline Black - Black-American Indian & $20.04-18.50=\underline{\mathbf{1 . 5 4}}$ & $18.98-20.01=\underline{\mathbf{- 1 . 0 3}}$ & $20.57-19.27=\underline{\mathbf{1 . 3 0}}$ \\
\hline Hispanic - White-Hispanic & $17.91-18.15=\mathbf{- 0 . 2 4}$ & $16.35-17.53=-\underline{\mathbf{1 . 1 8}}$ & $18.75-19.46=\mathbf{- 0 . 7 1}$ \\
\hline Hispanic - Black-Hispanic & $17.91-18.94=\underline{-\mathbf{1 . 0 3}}$ & $16.35-18.06=\underline{-\mathbf{1 . 7 1}}$ & $18.75-19.89=\mathbf{- \mathbf { 1 . 0 5 }}$ \\
\hline Hispanic - Hispanic-Asian & $17.91-17.97=\mathbf{- 0 . 0 6}$ & $16.35-19.59=\mathbf{- 3 . 2 4}$ & $18.75-20.71=-\underline{\mathbf{1 . 9 6}}$ \\
\hline Hispanic - Hispanic-American Indian & $17.91-18.98=-\underline{\mathbf{1 . 0 7}}$ & $16.35-18.01=\underline{-\mathbf{1 . 6 6}}$ & $18.75-19.78=-\underline{\mathbf{1 . 0 3}}$ \\
\hline Asian - White-Asian & $18.70-17.56=\underline{\mathbf{1 . 1 4}}$ & $18.61-16.27=\underline{\mathbf{2 . 3 4}}$ & $21.21-17.38=\underline{\mathbf{3 . 8 3}}$ \\
\hline Asian - Black-Asian & $18.70-23.59=-\underline{\mathbf{4 . 8 9}}$ & $18.61-16.79=\underline{\mathbf{1 . 8 2}}$ & $21.21-23.62=-\underline{\mathbf{2 . 4 1}}$ \\
\hline Asian - Hispanic-Asian & $18.70-17.97=\mathbf{0 . 7 3}$ & $18.61-19.59=\underline{-0.98}$ & $21.21-20.71=\mathbf{0 . 5 0}$ \\
\hline American Indian - White-American Indian & $15.76-15.89=-\mathbf{0 . 1 3}$ & $16.29-16.68=-\mathbf{0 . 3 9}$ & $17.93-18.55=\mathbf{- 0 . 6 2}$ \\
\hline American Indian - Black-American Indian & $15.76-18.50=\underline{-\mathbf{2 . 7 4}}$ & $16.29-20.01=-\underline{\mathbf{3 . 7 2}}$ & $17.93-19.27=\mathbf{- 1 . 3 4}$ \\
\hline American Indian - Hispanic-American Indian & $15.76-18.98=\underline{-\mathbf{3 . 2 2}}$ & $16.29-18.01=-\underline{\mathbf{1 . 7 2}}$ & $17.93-19.78=-\underline{\mathbf{1 . 8 5}}$ \\
\hline
\end{tabular}


Table 2

Tobit Regressions for the Age of First Cigarette, Alcohol, and Marijuana Use

\begin{tabular}{|c|c|c|c|}
\hline Variable & Cigarette & Alcohol & Marijuana \\
\hline Black & $4.002^{* * * *}(0.410)$ & $2.535^{* * *}(0.336)$ & $2.933^{* * *}(0.609)$ \\
\hline Hispanic & $1.036(0.958)$ & $-0.351(0.691)$ & $-0.703(1.504)$ \\
\hline Asian & $2.101^{* * *}(0.572)$ & $2.114^{* * *}(0.478)$ & $4.355^{* * *}(0.906)$ \\
\hline American Indian & $-1.629(0.982)$ & $-0.419(0.738)$ & $-2.172(3.006)$ \\
\hline White-Black & $4.514(2.399)$ & $1.051(1.117)$ & $1.446(3.096)$ \\
\hline White-Hispanic & $1.353^{* *}(0.473)$ & $0.914^{*}(0.392)$ & $0.636(0.731)$ \\
\hline White-Asian & $0.589(1.319)$ & $-0.443(0.696)$ & $-3.100 *(1.571)$ \\
\hline White-American Indian & $-1.472^{*}(0.692)$ & $-0.003(0.760)$ & $-1.075(1.138)$ \\
\hline Black-Hispanic & $2.424(2.451)$ & $1.494(1.479)$ & $1.489(3.034)$ \\
\hline Black-Asian & $10.252^{*}(4.559)$ & $0.115(1.192)$ & $10.953(6.090)$ \\
\hline Black-American Indian & $1.821(3.034)$ & $3.737(2.386)$ & $0.260(3.071)$ \\
\hline Hispanic-Asian & $1.124(1.957)$ & $3.246(2.000)$ & $3.227(3.398)$ \\
\hline Hispanic-American Indian & $2.473^{*}(1.113)$ & $1.444(0.943)$ & $1.272(1.755)$ \\
\hline Multirace/Other ${ }^{* * * *}$ & $0.732(1.305)$ & $0.278(0.843)$ & $-2.561(1.770)$ \\
\hline Age at wave 1 interview & $0.382^{* * *}(0.070)$ & $0.115^{*}(0.053)$ & $0.268^{* *}(0.102)$ \\
\hline Sex & $1.553^{* * *}(0.232)$ & $1.203^{* * *}(0.176)$ & $3.408^{* * *}(0.347)$ \\
\hline Family Structure & $1.500^{* * *}(0.286)$ & $0.430(0.228)$ & $2.083^{* * *}(0.430)$ \\
\hline \multicolumn{4}{|l|}{ Community Type } \\
\hline Suburban & $-1.696(0.253)$ & $-0.221(0.195)$ & $-0.273(0.380)$ \\
\hline Rural & $0.141(0.350)$ & $-0.421(0.256)$ & $0.793(0.533)$ \\
\hline \multicolumn{4}{|l|}{ Region } \\
\hline Midwest & $-1.162^{* *}(0.361)$ & $-1.035^{* * *}(0.272)$ & $-1.533^{* *}(0.516)$ \\
\hline South & $-1.214^{* * *}(0.325)$ & $-0.541^{*}(0.251)$ & $-0.490(0.470)$ \\
\hline Northeast & $-0.784(0.416)$ & $-0.582(0.302)$ & $-0.578(0.591)$ \\
\hline Closeness to mother figure & $0.604^{* * *}(0.150)$ & $0.520^{* * *}(0.122)$ & $0.765^{* *}(0.241)$ \\
\hline Lost mother figure & $11.351(6.060)$ & $5.543 *(2.392)$ & 86.260 \\
\hline Closeness to father figure & $1.010^{* * *}(0.123)$ & $0.644^{* * *}(0.111)$ & $1.586^{* * *}(0.199)$ \\
\hline Lost father figure & $2.337(10.660)$ & $6.837(5.114)$ & 0.593 \\
\hline Constant & $4.406^{* *}(1.663)$ & $11.414^{* * *}(1.312)$ & $11.984^{* * *}(2.500)$ \\
\hline Estimated SE of the Regression & $8.618(0.124)$ & $6.479(0.111)$ & $11.844(0.149)$ \\
\hline Pseudo R2 & 0.009 & 0.009 & .011 \\
\hline$N$ & 10557 & 10439 & 9876 \\
\hline
\end{tabular}

Standard Error in parentheses.

p $<0.05$

** $\mathrm{p}<0.01$, 
p $<0.001$

Multirace/Other refers to respondents who self-identified with three or more races/ethnicities or no races/ethnicities. 